\title{
Preparation, Hydrolysis and Storage Analysis of Alkaline Protease Microcapsules
}

\author{
Rui-Wen YANG ${ }^{1, a}$, Mei-Shuo ZHANG ${ }^{1, b}$, Song-Yi LIN ${ }^{1,2, c, *}$ \\ ${ }^{1}$ College of Food Science and Engineering, Jilin University, Changchun, 130062, P. R. China \\ ${ }^{2}$ School of Food Science and Technology, Dalian Polytechnic University, Engineering Research \\ Center of Seafood of Ministry of Education, Dalian 116034, P.R. China \\ amaomaoyrw@163.com, bzmeishuo@163.com, ${ }^{\mathrm{C}}$ linsongyi730@163.com \\ ${ }^{*}$ Corresponding author
}

Keywords: Alkaline Protease, Microcapsules, Preparation, Hydrolysis, Storage Analysis.

\begin{abstract}
Enzyme immobilization is a potential technology for many different industrial. Alkaline protease (AP) microcapsules were prepared with sodium alga acid (1.47\%), AP (0.78\%) and anhydrous calcium chloride $(2.93 \%)$. The mixture was placed for $1 \mathrm{~h}$ and the encapsulated rate of microcapsules achieved $96 \%$. The characterization of AP microcapsules and AP were identified. The microcapsules for enzymatic hydrolysis were optimized by one-factor-at-a-time (OFAT), and the optimum parameters were as follow: $\mathrm{pH}$ value was 11.0 , temperature was $50^{\circ} \mathrm{C}$, and microcapsules/casein $([\mathrm{M} / \mathrm{C}])$ was $6 \%$. The stability of AP microcapsules and AP were examined. The results showed that AP microcapsules had better stability than AP.
\end{abstract}

\section{Introduction}

Enzyme immobilization has attracted many researchers' interest for many different industrial applications $^{[1]}$. The process of immobilization should be mild enough to avoid degeneration of enzyme during preparation. The process is well fitted for the inclusion of biologically active molecules into both biologically functionalized films ${ }^{[2]}$ and micro and submicron sized capsules ${ }^{[3]}$ owing to the native conditions utilized in layer by layer (LbL) assembly ${ }^{[4,5]}$. Immobilization of enzyme into microcapsules is used for application to wastewater treatment owing to its degradation and recuperation of valuable components from effluent streams ${ }^{[6,7,8]}$. Immobilization of an enzyme extract or bacterial cells is increasingly used in biotechnology processes for bioremediation and biochemical conversion.

So far, alginate was used most widely as polymer for microencapsulation technologies ${ }^{[9,10]}$. Alginate is extracted from seaweed. It is composed of chains of alternating $\alpha$-l-guluronic acid and $\beta$-d-mannuronic acid residues ${ }^{[11]}$. Usually, the carboxyl group of the $\alpha$-l-guluronic acid crosslinked with a solution of a cationic crosslinker form alginate supports ${ }^{[12,13]}$. Calcium-alginate cross-linking method is simple, non-toxic and relatively mild-effect, so it is used widely for immobilization ${ }^{[14]}$.

The purpose of this work was to produce microcapsules of alkaline protease (AP) by Encapsulator B-395 Pro, according to the optimal parameters. Additionally, the characterization of AP microcapsules and AP were identified, including enzymatic hydrolysis and stability.

\section{Materials and Methods}

\section{Materials and Instruments}

Casein, trichloroacetic acid (TCA) and all the other materials required in the experiments were purchased from Beijing Chemical Plant. Standard sample of L-tyrosine was purchased from TCI Shanghai Co., Ltd. AP was purchased from China Pangbo Biological Engineering Co., Ltd. All chemicals and reagents were analytical grade. Encapsulator B-395 Pro was purchased from BUCHI, used for producing microcapsule. The main parts of the Encapsulator 8-395 Pro are the control unit, 
with the syringe pump, the electrical and pneumatic systems, and the reaction vessel.

\section{Microcapsules Preparation}

At room temperature, sodium alga acid (1.47\%) and AP $(0.78 \%)$ were mixed in a $100 \mathrm{~mL}$ beaker with a mechanical stirrer. The magnetic stirrer (IKA, Germany) was stirred at $1500 \mathrm{r} / \mathrm{min}$ for $1 \mathrm{~h}$. The $30 \mathrm{~mL}$ mixture was drawn into a $50 \mathrm{~mL}$ syringe. Washing solution was made by anhydrous calcium chloride (2.93\%). The Encapsulator B-395 Pro was set as follow: stirrer 40\%, pump $5.01 \mathrm{~mL} / \mathrm{min}$, electrode $1550 \mathrm{~V}$, frequency $1900 \mathrm{~Hz}$ and nozzle $0.20 \mathrm{~mm}$. At the conclusion of the production run, the mixture was set at room temperature for $1 \mathrm{~h}$. The microcapsules and liquid were separated through a sterile filter. The filtrate was collected for determination of enzyme activity. The microcapsules were separated from the outer water phase, rinsed three times with distilled water and freeze-dried (Freeze Drier, Christ ALPHA 1-2LD plus, Germany) for 24h (as a batch). The encapsulated rate of microcapsules was determined as Eq.1.

$$
\text { Encapsulated rate }(\%)=\frac{\text { Addition of enzyme activity }- \text { Remain of enzyme activity }}{\text { Addition of enzyme activity }} \times 100 \%
$$

Enzymatic activity of the microcapsules was carried out by the method described by Kembhavi et al. [15].

\section{Characterization of the AP Microcapsules}

Optimum Condition of the Microcapsules for Enzymatic Hydrolysis. In our study, the AP microcapsules prepared were pulverized in $100 \mathrm{mM}$ pH 7.4 phosphate buffer saline (PBS) buffer solutions by a mortar for pounding, then kept on a rotary shaker of $150 \mathrm{r} / \mathrm{min}$ for $15 \mathrm{~min}$. The mixture was centrifuged at $3000 \mathrm{r} / \mathrm{min}$ for $1 \mathrm{~min}$ to gain supernatant liquid. Activity of the supernatant liquid was determined for enzymatic hydrolysis. Three independent variables were studied, including $\mathrm{pH}$ value for microcapsules $(8.0,9.0,10.0,11.0$, and 12.0), temperature $(30,40$, 50,60 and $\left.70^{\circ} \mathrm{C}\right)$, and microcapsules/casein $([\mathrm{M} / \mathrm{C}])(2,4,6,8$ and $10 \%)$, respectively. At the same time, activity of AP was determined as control. Each text changed only one variable value and other variables were fixed.

Storage of AP Microcapsules. AP-containing microcapsules were stored in $100 \mathrm{mM} \mathrm{pH} 7.4 \mathrm{PBS}$ buffer solutions at $20^{\circ} \mathrm{C}$. Enzymatic activity of the microcapsules was determined according to the procedure described above. Before determination, the microcapsules were pulverized in $100 \mathrm{mM} \mathrm{pH}$ 7.4PBS solution and centrifuged as described above.

Statistical Analysis. All experiment represented the mean of three determinations carried out. The SPSS 13.0 software (SPSS Inc., Chicago, IL, USA) A level of significance $p=0.05$ was considered significant. One-way ANOVA was used to analyze the results of triplicate.

\section{Results and Discussion}

\section{Characterization of the AP Microcapsules}

Optimum Condition of the Microcapsules for Enzymatic Hydrolysis. The effect of $\mathrm{pH}$ from 8.0 to 12.0 on activity of AP microcapsules was determined (Fig.1). The optimum for enzymatic activity of the microcapsules was at $\mathrm{pH}$ 11.0. Enzymatic activity of the microcapsules increased significantly with the $\mathrm{pH}$ value increasing from 8.0 to $10.0(P<0.05)$. However, enzymatic activity of AP increased when $\mathrm{pH}$ value increased from 8.0 to 10.0 and reached the highest value $1365.64 \pm$ $27.77 \mathrm{U}$ at $\mathrm{pH}$ 10.0. As for the effect of temperature, the enzymatic activity of AP microcapsules reached the highest value of $981.27 \pm 34.23 \mathrm{U}$ when the temperature was $50^{\circ} \mathrm{C}$ (Fig.1). The enzymatic activity of AP also reached the highest value with the temperature $50^{\circ} \mathrm{C}$ (Fig.1). As shown in Fig.1, the effect of M/C ratio from 2\% to $10 \%$ on enzymatic activity of AP microcapsules was determined. Increasing of M/C ratio leaded to an increase in enzymatic activity when the M/C 
ratio increased from $2 \%$ to $6 \%$. Hence, the optimum $\mathrm{M} / \mathrm{C}$ ratio for hydrolysis of casein by the enzyme was at $6 \%$. The hydrolysate showed maximum enzymatic activity of AP at $4 \%$. There were some differences between AP and AP microcapsules for enzymatic hydrolysis.
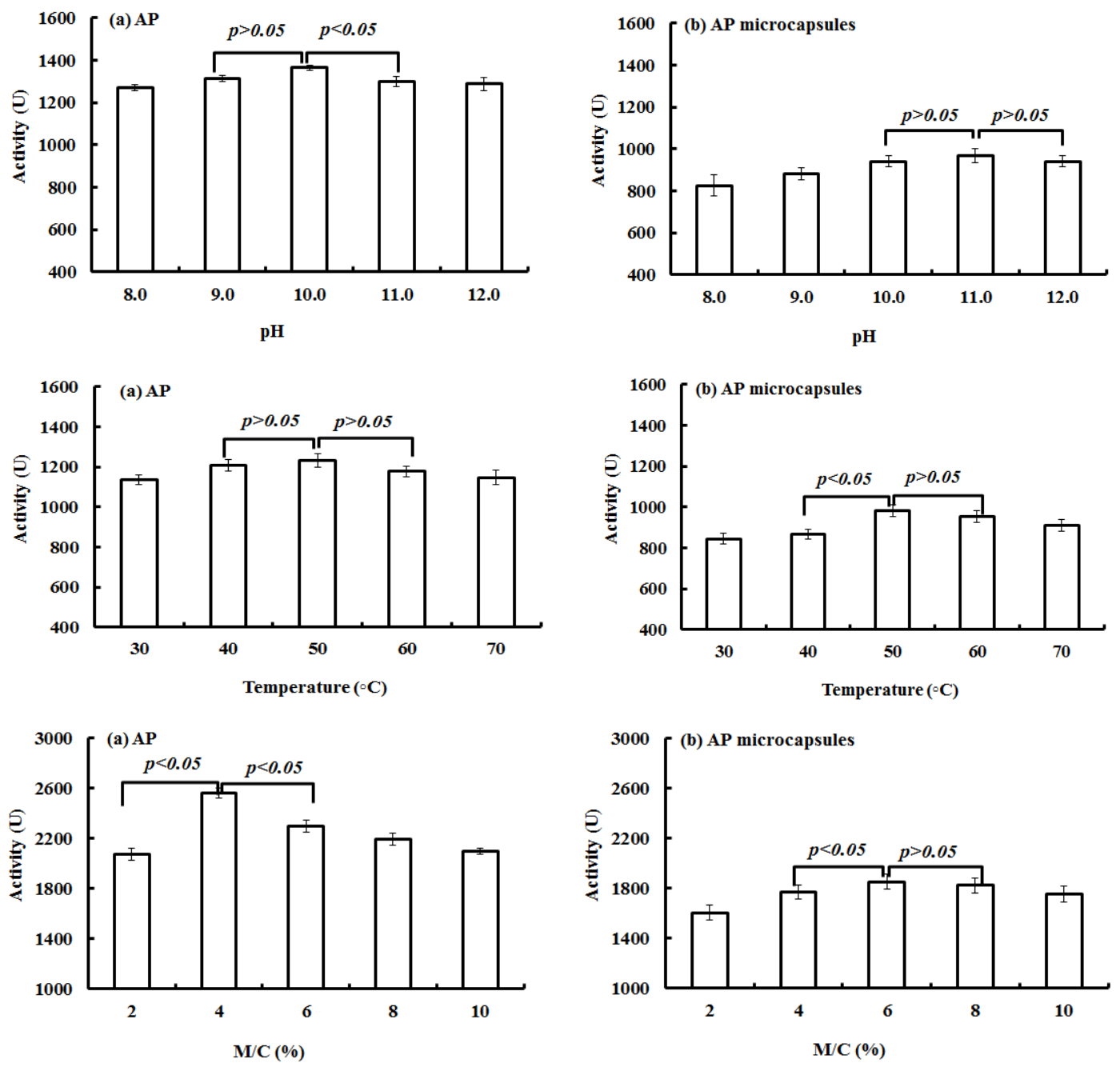

Fig.1 Characterization of the AP Microcapsules (the Effect of Hydrolysis pH, Temperature and [M/C] Ratio on the Activity of AP and AP Microcapsules)

Storage of AP Microcapsules. The stability of the AP microcapsules stored at $20^{\circ} \mathrm{C}$ was tested $(\mathrm{n}=3)$. The AP also stored at $20^{\circ} \mathrm{C}$. The total amount of encapsulated AP in $1 \mathrm{~mL}$ of microcapsule suspension was calculated to be $12.7578 \mathrm{mg}$, according to the mass ratio. Enzymatic activity of the same amount $(12.7578 \mathrm{mg})$ of free AP to casein was determined to be the control. Enzymatic activity of AP microcapsules was determined every eight hours. The AP microcapsules prepared were pulverized in $100 \mathrm{mM}$ phosphate buffer saline solution by a mortar for pounding, and then kept on a rotary shaker for $15 \mathrm{~min}$ at $150 \mathrm{r} / \mathrm{min}$. The enzyme activity was showed in the Fig.2. Enzymatic activity of AP and AP microcapsules reduced significantly as time went by. However, enzymatic activity of AP reduced more quickly than AP microcapsules. From the Fig.2, half-time of activity was $320 \mathrm{~h}$ for AP microcapsules as possible. It's longer than half-time of AP. The excellent stability of the AP microcapsules would apply to their store. 


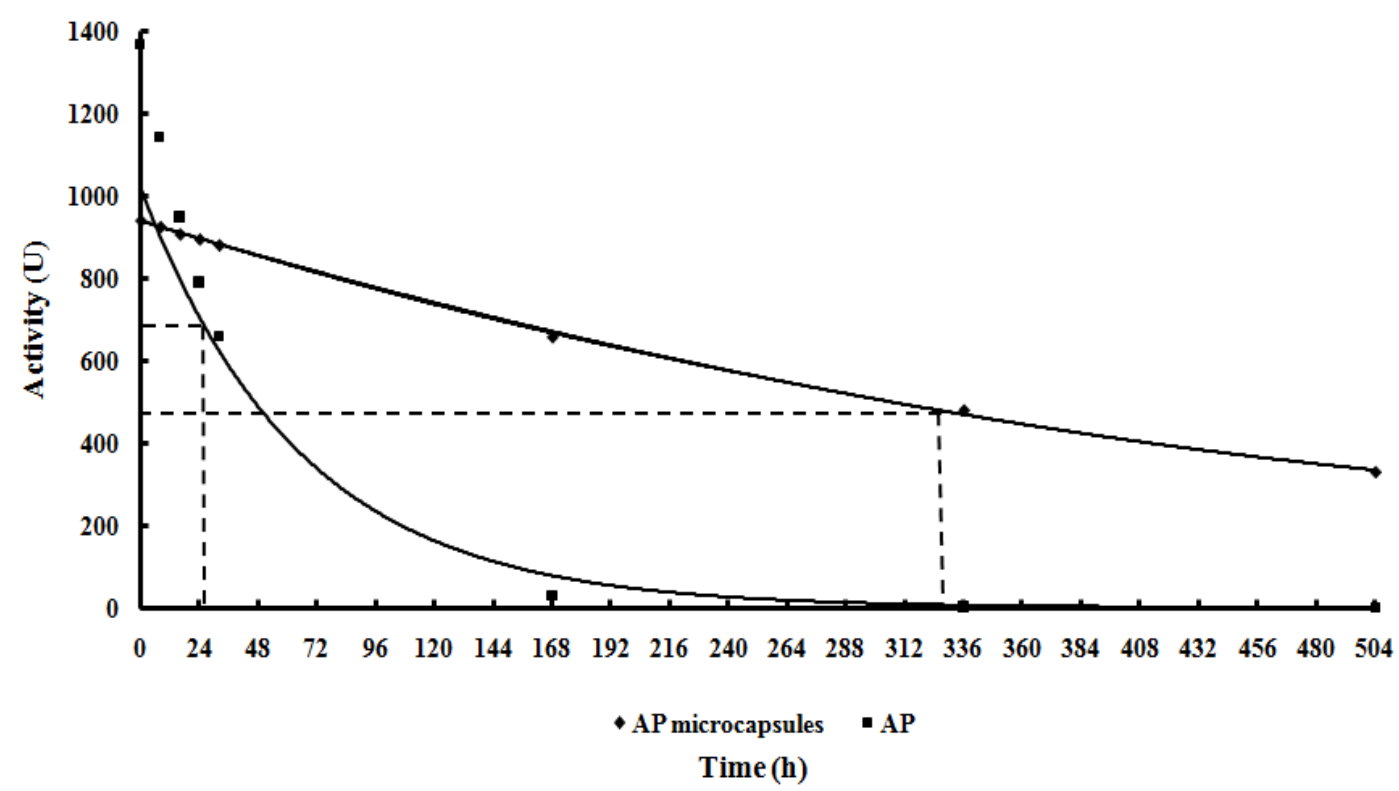

Fig.2 The Storage of AP and AP Microcapsules

\section{Summary}

In this paper, alkaline protease (AP) microcapsules with $96 \%$ encapsulated rate were prepared. The characterization, including enzymatic hydrolysis and stability, of AP microcapsules and AP were identified. The enzymatic hydrolysis was optimized by OFAT. The results showed that the optimum parameters were as follow: $\mathrm{pH}$ value was 11.0 , temperature was $50^{\circ} \mathrm{C}$, and microcapsules/casein $([\mathrm{M} / \mathrm{C}])$ was $6 \%$. AP microcapsules were better than AP at stability that would contribute to their store.

\section{Acknowledgement}

The authors acknowledge the financial support provided by the Key Projects of Jilin province Science \& Technology Program (20150204032NY) and the Changchun Science and Technology Planning Project of Modern Agricultural Science and Technology Support Special (14NK005).

\section{References}

[1] R. Taylor, Protein immobilization: fundamentals and applications Marcel Dekker Inc, New York, NY, 1991.

[2] G. Decher, J.D. Hong, J. Schmitt, Buildup of ultrathin multilayerfilms by a selfassembly process: III. Consecutively alternating adsorption of anionic and cationic polyelectrolytes on charged surfaces, Thin Solid Films. 210-211 (1992) 831-835.

[3] G. Sukhorukov, E. Donath, S. Davis, H. Lichtenfeld, F. Caruso, V. Popov, et al., Step-wise polyelectrolyte assembly on particle surfaces - anovel approach to colloid design, Polym. Adv. Technol. 9 (1998) 759-767.

[4] K. Ariga, Q.J. Ji, Enzyme-encapsulated layer-by-layer assemblies: current status and challenges toward ultimate nanodevices, Adv. Polym. Sci. 229 (2010) 51-87.

[5] S. Koker De, R. Hoogenboom, B.G. Geest De, Polymeric multilayer capsules for drug delivery, Chem. Soc. Rev. 41 (2012) 2867-2884.

[6] A. Wyss, J. Boucher, A. Montero, I. Marison, Micro-encapsulated organic phase for enhanced 
bioremediation of hydrophobic organic pollutants, Enzyme Microb. Tech. 40 (2006) 25-31.

[7] L. Giorno, E. Drioli, Biocatalytic membrane reactors: applications and perspectives, Trends Biotechnol. 18 (2000) 339-349.

[8] C. López, I. Mielgo, M.T. Moreira, G. Feijoo, J.M. Lema, Enzymatic membrane reactors for biodegradation of recalcitrant compounds, Biotechnol. 99 (2002) 249-257.

[9] G. Funduenanu, C. Nastruzzi, A. Carpov, J. Desbrieres, M. Rinaudo, Physico-chemical characterization of Ca-alginate microparticles produced by different methods, Biomaterials. 20 (1999) 1427-1435.

[10] F. Velten, C. Laue, J. Schrezenmeir, The effect of alginate and hyaluronate on the viability and function of immunoisolated neonatal rat islets, Biomaterials. 20 (1999) 2161-2167.

[11] P. Sriamornsak, Preliminary investigation of some polysaccharides as a carrier for cell entrapment, Eur. J. Pharm. Biopharm. 46 (1998) 233-236.

[12] K.I. Draget, G. Skjak-Braek, O. Smidsrod, Alginate based new materials, Int. J. Biol. Macromol. 21 (1997) 47-55.

[13] O. Smidsrod, G. Skak-Braek, Alginate as immobilization matrix for cells, Trends. Biotechnol. 8 (1990) 71-78.

[14] J. Ha, C.R. Engler, J.R. Wild, Biodegradation of coumaphos, chlorferon, and diethylthiophosphate using bacteria immobilized in Ca-alginate gel beads, Bioresour. Technol. 100 (2009) 1138-1142.

[15] A.A. Kembhavi, A. Kulharni, A.A. Pant, Salt-tolerant and thermostable alkaline protease from Bacillus subtilis NCIM No. 64, Appl. Biochem. Biotechnol. 38 (1993) 83-92. 